\title{
Long non-coding RNA PART1 promotes intervertebral disc degeneration through regulating the miR-93/MMP2 pathway in nucleus pulposus cells
}

\author{
DONGMEI GAO ${ }^{1}$, LONG HAO ${ }^{1}$ and ZILONG ZHAO $^{2}$ \\ ${ }^{1}$ Department of Pain Rehabilitation, Yan'an University Affiliated Hospital, Yan'an, Shaanxi 716000; \\ ${ }^{2}$ Department of Pathology, Ankang Central Hospital, Ankang, Shaanxi 725000, P.R. China
}

Received October 21, 2019; Accepted March 11, 2020

DOI: $10.3892 /$ ijmm.2020.4580

\begin{abstract}
The aim of the present study was to investigate the role of the long non-coding (lnc)RNA PART1 in nucleus pulposus (NP) cells derived from patients with intervertebral disc degeneration (IDD). The level of PART1 in degenerative NP tissues from patients with IDD, bulging and herniated discs was measured by reverse transcription-quantitative PCR (RT-qPCR) analysis. NP cells were isolated from patients with IDD and transfected with siPART1, after which time the growth ability of the NP cells was evaluated by Cell Counting Kit-8 and colony formation assays, and cell apoptosis was measured by flow cytometry. The levels of the cell proliferation marker Ki-67 and the apoptosis marker cleaved caspase-3, and the levels of genes related to extracellular matrix (ECM) synthesis and degradation, were also evaluated by western blotting and RT-qPCR, as appropriate. Bioinformatics methods predicted that miR-93 was sponged by PART1, and matrix metallopeptidase (MMP)2 was targeted by miR-93, which was further confirmed by dual-luciferase reporter assay. The levels of miR-93 and MMP2 were also measured in NP tissues, and further rescue experiments were performed to confirm the role of the PART1/miR-93/MMP2 pathway in NP cells. PART1 was found to be upregulated in degenerative NP tissues, and siPART1 caused an increase in cell growth ability and ECM synthesis, whereas it decreased cell apoptosis and ECM degradation in NP cells. miR-93 was downregulated and MMP2 was upregulated in degenerative NP tissues. Rescue experiments indicated that the effects of miR-93 inhibitor on
\end{abstract}

Correspondence to: Dr Zilong Zhao, Department of Pathology, Ankang Central Hospital, 85 South Jinzhou Road, Hanbin, Ankang, Shaanxi 725000, P.R. China

E-mail: zhaozil_zilong@163.com

Abbrevations: NP, nucleus pulposus; IDD, intervertebral disc degeneration; MSC, mesenchymal stem cell

Key words: nucleus pulposus, intervertebral disc degeneration, PART1, microRNA-93, matrix metallopeptidase 2
NP cells were abolished by siPART1, and the effect of miR-93 mimic on NP cells was rescued by MMP2 overexpression. Thus, the results of the present study demonstrated that PART1 may regulate NP cell degeneration through the miR-93/MMP2 pathway. These findings indicate a novel signaling axis in NP cells that may be explored for the treatment of IDD.

\section{Introduction}

Intervertebral disc degeneration (IDD) is a chronic and high-incidence musculoskeletal disorder that causes back/neck and radicular-related pain, with a worldwide socioeconomic impact (1).

The intervertebral disc is composed of the external annulus fibrosus (AF) and the inner gel-like nucleus pulposus (NP). NP cells play a prominent role in both normal intervertebral discs and the pathogenesis of IDD. Normal NP tissues are responsible for distributing hydraulic pressure to the AF and endplate, while reduced numbers of NP cells, loss of proteoglycan and changes in the biomechanics of the spinal column lead to NP tissue degeneration and low back pain (2). In addition, mechanical overloading-induced NP cell apoptosis contributes to the development of IDD. Therefore, research on NP cells remains a major challenge in IDD treatment (3-5). Identifying factors that exert anti-senescent or anti-apoptotic effects on NP cells appears to be a promising approach. For example, sirt6 has shown potent anti-senescent and anti-apoptotic properties in models of age-related degenerative disease (6). Furthermore, overproduction of reactive oxygen species (ROS) has been reported to be involved in the senescence and apoptosis of NP cells and may accelerate the degenerative process (7). Previous studies also demonstrated that tumor necrosis factor- $\alpha$ promotes changes in the production of extracellular matrix (ECM) molecules, tissue degradation (8) and premature senescence of NP cells $(9,10)$. However, the molecular mechanisms underlying NP cell growth, differentiation and senescence are incompletely understood.

Long non-coding RNAs (lncRNAs), which contain >200 nucleotides (some may contain $>100,000$ nucleotides), play an important role in variety of human diseases, including IDD (11). Several lncRNAs are dysregulated in human degenerative NP tissues, and some participate in multiple 
pathological processes, including inflammatory responses, ECM degradation, angiogenesis and apoptosis (12). LncRNA PART1 has been shown to be a potential prognostic biomarker and therapeutic target for tongue squamous cell carcinoma (13), hepatocellular carcinoma (14) and non-small cell lung cancer (15). It was also recently demonstrated that PART1 regulates apoptosis and proliferation in prostate cancer cells through toll-like receptor pathways (16). However, the role of lncRNA PART1 in NP cells and IDD has yet to be reported.

The aim of the present study was to investigate the role of PART1 in NP cells derived from patients with IDD, hoping to improve our understanding of the mechanisms underlying the degeneration of NP cells.

\section{Materials and methods}

Patients and tissue samples. Human lumbar NP specimens were obtained from 120 patients with spinal cord injury [control $(n=30)$, IDD $(n=30)$, bulging discs $(n=30)$ and herniated discs $(n=30)]$ from Yanan University Affiliated Hospital. All the patients underwent surgery at Yanan University Affiliated Hospital between 2015 and 2017. The present study was approved by the Ethics Committee of Yanan University Affiliated Hospital, and written informed consent was obtained from each participant prior to surgery.

Isolation and culture of human NP cells. NP tissues from 10 patients with IDD were separated and washed using Hank's solution (14025126, Gibco; Thermo Fisher Scientific, Inc.). Subsequently, the samples were cut into $1-\mathrm{mm}^{3}$ pieces, centrifuged at $500 \mathrm{x} \mathrm{g}$ for $5 \mathrm{~min}$ at $4^{\circ} \mathrm{C}$, and then treated with type II collagenase $(0.2 \%$; 17101015 , Gibco; Thermo Fisher Scientific, Inc.) at $37^{\circ} \mathrm{C}$ for $4-6 \mathrm{~h}$. Next, the tissues were centrifuged at $500 \mathrm{x} \mathrm{g}$ for $8 \mathrm{~min}$ at $4^{\circ} \mathrm{C}$, and DMEM/F12 (11320033, Gibco; Thermo Fisher Scientific, Inc.) was added for cell suspension and centrifugation. When the cell density reached $5 \times 10^{5} / \mathrm{ml}$, the cells were seeded into culture flasks and cultured at $37^{\circ} \mathrm{C}$ in DMEM/F12 supplemented with fetal bovine serum (16140071, Gibco; Thermo Fisher Scientific, Inc.), L-glutamine (25030081, Gibco; Thermo Fisher Scientific, Inc.), and 1\% streptomycin and penicillin (10378016, Gibco; Thermo Fisher Scientific, Inc.) at $37^{\circ} \mathrm{C}$ with $5 \% \mathrm{CO}_{2}$. Cells were observed under a DMi8 optical microscope (Leica Microsystems $\mathrm{GmbH}$ ), at a magnification of $\mathrm{x} 100$ and $\mathrm{x} 200$.

Collagen II immunofluorescence staining. Collagen II was detected using immunofluorescence staining. First, NP cells were fixed with $4 \%$ paraformaldehyde for $20 \mathrm{~min}$ at room temperature, blocked with goat serum (Solarbio) for $30 \mathrm{~min}$, then incubated with collagen II primary antibody $(1: 200$, ab34712, Abcam) for $1 \mathrm{~h}$, and goat anti-rabbit IgG H\&L secondary antibody (1:500, ab150077, Abcam) for $45 \mathrm{~min}$. Finally, the cells were stained with $0.5 \mu \mathrm{g} / \mathrm{ml}$ 4',6-diamidino-2phenylindole (DAPI; Sigma-Aldrich; Merck KGaA) at room temperature for $10 \mathrm{~min}$, and observed under a DM13000B fluorescence microscope (Leica Microsystems $\mathrm{GmbH}$ ) at a magnification of $\mathrm{x} 100$.

Cell transfection. The small interfering RNA against PART1 (17) (5'-GCA AAUGAAAGCUACCAAU-3') was purchased from GenePharma Co., Ltd. SiPART1 (siG000004313A-1-5), control siRNA (siN0000001-1-5), mimic control (miR1N0000001-1-5), miR-93 mimic (miR10004976-1-5), inhibitor control (miR2N0000001-1-5) and miR-93 inhibitor (miR20012845-1-5) were synthesized by Ribobio Co., Ltd. The full length of matrix metallopeptidase (MMP)2 was amplified and inserted into the pcDNA 3.1 plasmid (V79020, Invitrogen; Thermo Fisher Scientific, Inc.). The pcDNA 3.1-MMP2 was then transfected into the cells to achieve MMP2 overexpression. The vector pcDNA 3.1 plasmid was transfected into cells as control. Opti-MEM (11058021, Invitrogen; Thermo Fisher Scientific, Inc.) containing Lipofectamine ${ }^{\circledR} 2000$ (11668019, Invitrogen; Thermo Fisher Scientific, Inc.) was used to transfect mimic, control mimic or plasmids into the cells at room temperature for $10 \mathrm{~min}$. All the transfection procedures were performed following the manufacturer's instructions. After incubation for $24 \mathrm{~h}$, the cells were collected for further experiments.

RNA isolation and reverse transcription-quantitative PCR $(R T-q P C R)$ analysis. Tissue specimens were placed in liquid nitrogen and homogenized using TRIzol reagent (15596018, Invitrogen; Thermo Fisher Scientific, Inc.) at $4^{\circ} \mathrm{C}$. Total RNA was isolated from each sample at $4^{\circ} \mathrm{C}$ using the Qiagen RNeasy Plus Mini Kit (74134, Qiagen $\mathrm{GmbH}$ ) according to the manufacturer's protocol. The cells were treated with TRIzol reagent and total RNA was extracted using chloroform and isopropanol at $4^{\circ} \mathrm{C}$. NanoDrop 8000 (ND-8000-GL, Thermo Fisher Scientific, Inc.) was used to assess the concentration of RNAs.

For quantification of mRNAs, the PrimeScript ${ }^{\mathrm{TM}}$ II 1st Strand cDNA Synthesis Kit (6210B, Takara Bio, Inc.) was used for reverse transcription $\left(42^{\circ} \mathrm{C}\right.$ for $\left.15 \mathrm{~min}\right)$, and $\mathrm{SYBR}^{\circledR}$ Green PCR Master Mix (4312704, Applied Biosystems; Thermo Fisher Scientific, Inc.) and Bio-Rad CFX 96 Touch Real-Time PCR Detection System (1855196, Bio-Rad Laboratories, Inc.) were then used for qPCR. The thermocycling conditions were as follows: $95^{\circ} \mathrm{C}$ for $5 \mathrm{~min}$, followed by 40 cycles at $95^{\circ} \mathrm{C}$ for $15 \mathrm{sec}, 60^{\circ} \mathrm{C}$ for $30 \mathrm{sec}$, and $70^{\circ} \mathrm{C}$ for $10 \mathrm{sec}$. GAPDH served as an internal control and the $2^{-\Delta \Delta \mathrm{Cq}}$ method was used to calculate the relative gene expression (18). All reactions were performed for three mechanical duplications. All primers for RT-qPCR are listed in Table I.

For miR-93 quantification, cDNA was prepared from total RNA $(2 \mu \mathrm{g})$ by using One-Step miRNA RT kit (D1801, HaiGene). The SYBR Green miRNA RT-qPCR kit for amplifying miR-93 (AP01605, HaiGene) and U6 snRNA (AP02055, HaiGene) were used in RT-qPCR, and the parameters were set as follows: $95^{\circ} \mathrm{C}$ for $5 \mathrm{~min}$, followed by 40 cycles at $95^{\circ} \mathrm{C}$ for $15 \mathrm{sec}, 60^{\circ} \mathrm{C}$ for $30 \mathrm{sec}$ and $70^{\circ} \mathrm{C}$ for $10 \mathrm{sec}$. U6 snRNA served as an internal control. The comparative quantification cycle method $2^{-\Delta \Delta C q}$ was used to calculate the relative gene expression.

Cell Counting Kit (CCK)-8 assay. The cells ( $1 \times 10^{4}$ cells/well) were inoculated onto a 96 -well plate containing $100 \mu \mathrm{l}$ medium, with each experiment comprising 6 duplicated wells and 5 zero wells. The cells were cultured with $5 \% \mathrm{CO}_{2}$ at $37^{\circ} \mathrm{C}$, and $10 \mu \mathrm{l} \mathrm{CCK-8} \mathrm{solution} \mathrm{(70-CCK801,} \mathrm{MultiSciences)} \mathrm{was} \mathrm{added}$ into each well at 24,48 and $72 \mathrm{~h}$ of culture. After incubation for $2 \mathrm{~h}$ at $37^{\circ} \mathrm{C}$, the absorbance value at $490 \mathrm{~nm}$ was detected 
Table I. Primers used for reverse transcription-quantitative PCR analysis.

\begin{tabular}{lll}
\hline Gene & \multicolumn{1}{c}{ Forward primer $\left(5^{\prime}-3^{\prime}\right)$} & \multicolumn{1}{c}{ Reverse primer $\left(5^{\prime}-3^{\prime}\right)$} \\
\hline PART1 & AAGGCCGTGTCAGAACTCAA & GTTTTCCATCTCAGCCTGGA \\
Aggrecan & ACTCTGGGTTTCGTGACTCT & ACACTCAGCGAGTTGTCATGG \\
ADAMTS4 & GAGGAGGAGATCGTGTTTCCA & CCAGCTCTAGTAGCAGCGTC \\
Collagen II & TGGACGATCAGGCGAAACC & GCTGCGGATGCTCTCAATCT \\
MMP13 & ACTGAGAGGCTCCGAGAAATG & GAACCCCGCATCTTGGCTT \\
MMP2 & ATCCAGACTTCCTCAGGCGG & CCATTAGCGCCTCCATCGTAG \\
GAPDH & TGTGGGCATCAATGGATTTGG & ACACCATGTATTCCGGGTCAAT
\end{tabular}

MMP, matrix metallopeptidase.

by the SpectraMax Plus 384 Microplate Reader (PLUS 384, Molecular Devices, LLC).

Colony formation assay. The cells (200 cells/well) were seeded in a 12-well plate and cultured continuously for 14 days. All subsequent clones were stained using $0.5 \%$ crystal violet solution (548-62-9, Aladdin) for $10 \mathrm{~min}$ at room temperature, and counted under a DMi8 optical microscope (Leica Microsystems $\mathrm{GmbH}$ ), at a magnification of x100. Clusters of $>50$ cells were considered as colonies, and the colony formation rate was then calculated in five fields of view.

Flow cytometry. Apoptosis was evaluated using an Annexin-V kit (70-AP101-100-AVF, MultiSciences). Briefly, after trypsinization, $1-5 \times 10^{6}$ cells were pelleted and centrifuged at $450 \mathrm{xg}$ for $5 \mathrm{~min}$ at $4^{\circ} \mathrm{C}$. The cells were then resuspended in $300 \mu \mathrm{l}$ binding buffer, and $5 \mu \mathrm{l}$ Annexin-V-FITC solution was added and incubated with the cells at room temperature for $15 \mathrm{~min}$ in the dark. The nuclei were stained with $5 \mu \mathrm{l}$ PI for $5 \mathrm{~min}$ at room temperature. Finally, another $200 \mu \mathrm{l}$ binding buffer was added, and cell apoptosis was evaluated.

Western blot analysis. Total protein samples were extracted from NP cells using lysis buffer (89901, Thermo Fisher Scientific, Inc.) with a protease inhibitor (36978, Thermo Fisher Scientific, Inc.). Equal amounts of protein $(60 \mu \mathrm{g} /$ lane $)$ were separated on $8 \%$ SDS-polyacrylamide gels and then transferred to a PVDF membrane (LC2002, Invitrogen; Thermo Fisher Scientific, Inc.). The membrane was then blocked by 5\% non-fat milk (PA201-01, BioMed) for $10 \mathrm{~min}$ at room temperature and then incubated with the primary antibodies: Anti-Ki-67 (1:5,000, ab92742, Abcam), anti-cleaved (C)-caspase-3 (1:500, ab2302, Abcam), anti-aggrecan (1:100, ab3778, Abcam), anti-ADAMTS4 (1:1,000, ab185722, Abcam), anti-collagen II (1:2,000, ab34712, Abcam), anti-MMP13 (1:3,000, ab39012, Abcam) and anti-GAPDH (1:2,000, ab8245, Abcam) at $4{ }^{\circ} \mathrm{C}$ overnight. The membrane was then incubated with HRP-linked anti-rabbit IgG secondary antibody (1:5,000; 7074, Cell Signaling Technology, Inc.) for Ki-67, C-caspase-3, ADAMTS4, collagen II, MMP13, or incubated with HRP-conjugated anti-mouse IgG (1:5,000, 7076, Cell Signaling Technology, Inc.) for aggrecan and GAPDH at $4{ }^{\circ} \mathrm{C}$ overnight. Finally, SignalFire ${ }^{\mathrm{TM}}$ ECL reagent $(6883$, Cell Signaling Technology, Inc.) and ImageQuant ECL Imager
(28-9605-63, GE Healthcare) were used to detect the signals. Prior to each incubation, $1 X$ TBST (50 mM Tris, $150 \mathrm{mM} \mathrm{NaCl}$ and $2 \%$ Tween-20, $\mathrm{pH} 7.5$ ) was used to wash the membrane three times, 5 min per wash. GADPH served as an internal control.

Dual-luciferase reporter assay. PART1-wild-type (WT), PART1-mutant (MUT), MMP2-WT and MMP2-MUT were synthesized by Tsingke Co., Ltd. and separately cloned into luciferase reporter gene vector (pmirGLO, E1330, Promega Corporation) to construct luciferase reporter plasmids. Renilla luciferase in the reporter plasmid served as the internal control. Briefly, cells cultured in 96-well plates were transfected with luciferase reporter plasmids $(0.05 \mu \mathrm{g} /$ well $)$, or co-transfected with luciferase reporter plasmids and miR-93 inhibitor, or miR-93 mimic (15 $\mathrm{nM})$. After transfection for $24 \mathrm{~h}$, the cells were analyzed for luciferase activity using the Dual-Glo ${ }^{\circledR}$ Luciferase assay system (E2920, Promega Corporation) and a Microplate Luminometer (11300010, Berthold Technologies). The ratio of firefly luciferase activity relative to that of Renilla luciferase activity was calculated.

Statistical analysis. All statistical analyses were conducted using SPSS v.19.0 software (IBM Corp.). Graph presentations were created using GraphPad Prism 5.02 (GraphPad Software, Inc.). The data are presented as percentage \pm standard error of the mean. Data were analyzed by Student's t-test or ANOVA followed by Tukey's post hoc test in SPSS. P $<0.05$ was considered to indicate statistically significant differences.

\section{Results}

Expression of lncRNA PART1 in NP tissues and the effects of lncRNA PART1 on NP cells. The expression level of lncRNA PART1 was measured in NP tissues from patients with IDD or controls, and PART1 was found to be highly expressed in NP tissues from patients with IDD ( $\mathrm{P}<0.001$, Fig. 1A). The expression level of PART1 in herniated NP tissues was the highest compared with control and bulging NP tissues $(\mathrm{P}<0.001$, Fig. 1B). Subsequently, NP cells were isolated from patients with IDD and examined using an optical microscope. The cultured NP cells were polygonal or spindle-shaped, displaying short pseudopods. Upon approaching confluence, the cells exhibited swirling or formation of flame-like cell 
A
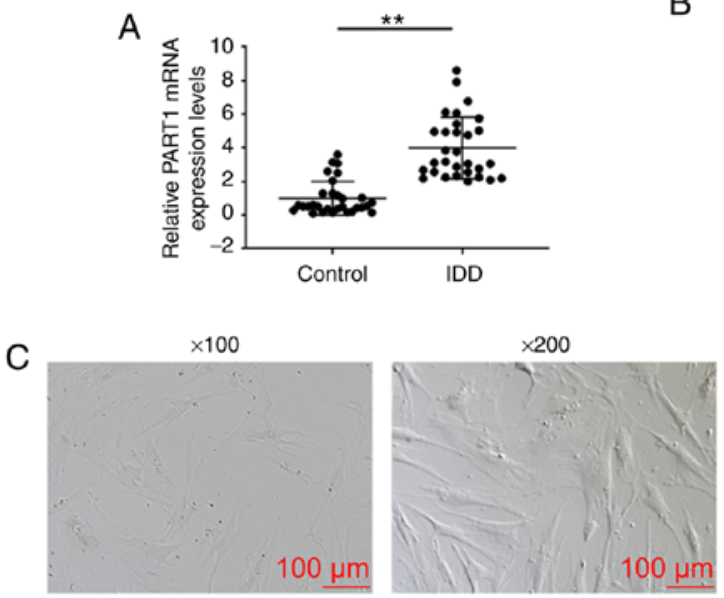

B

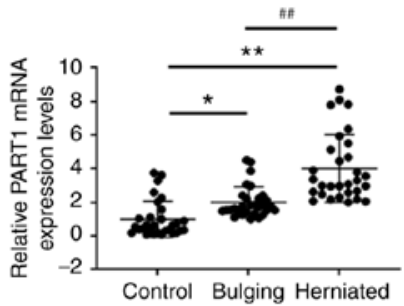

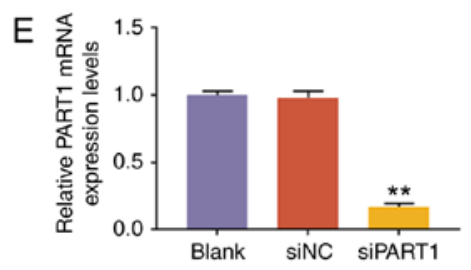

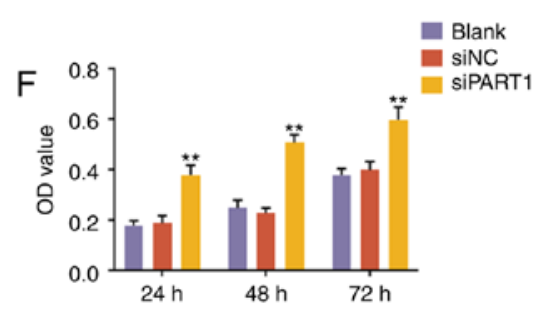

G

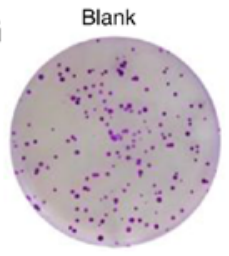

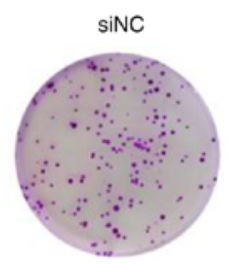
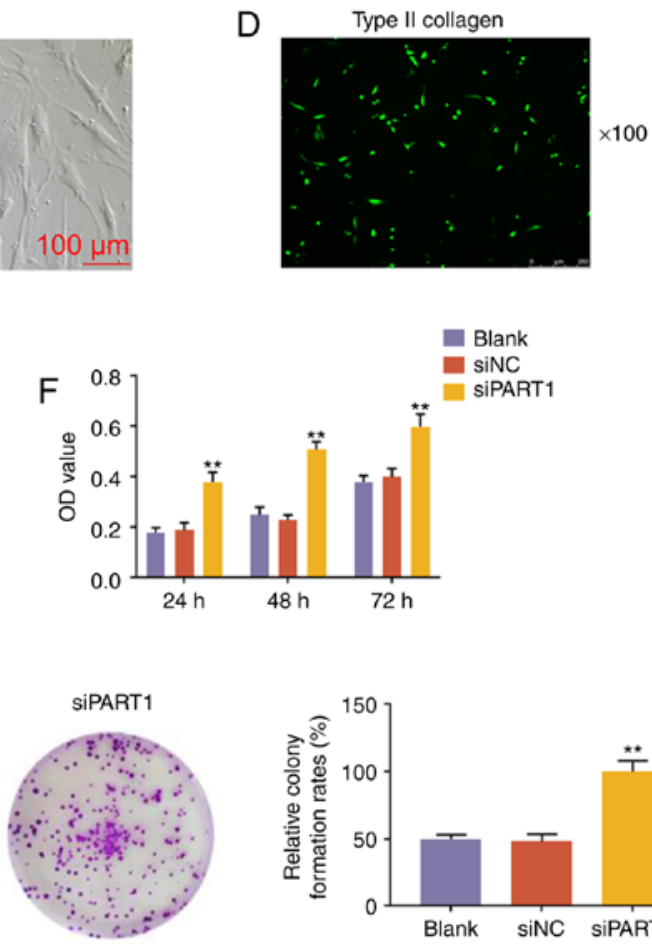

$\times 100$
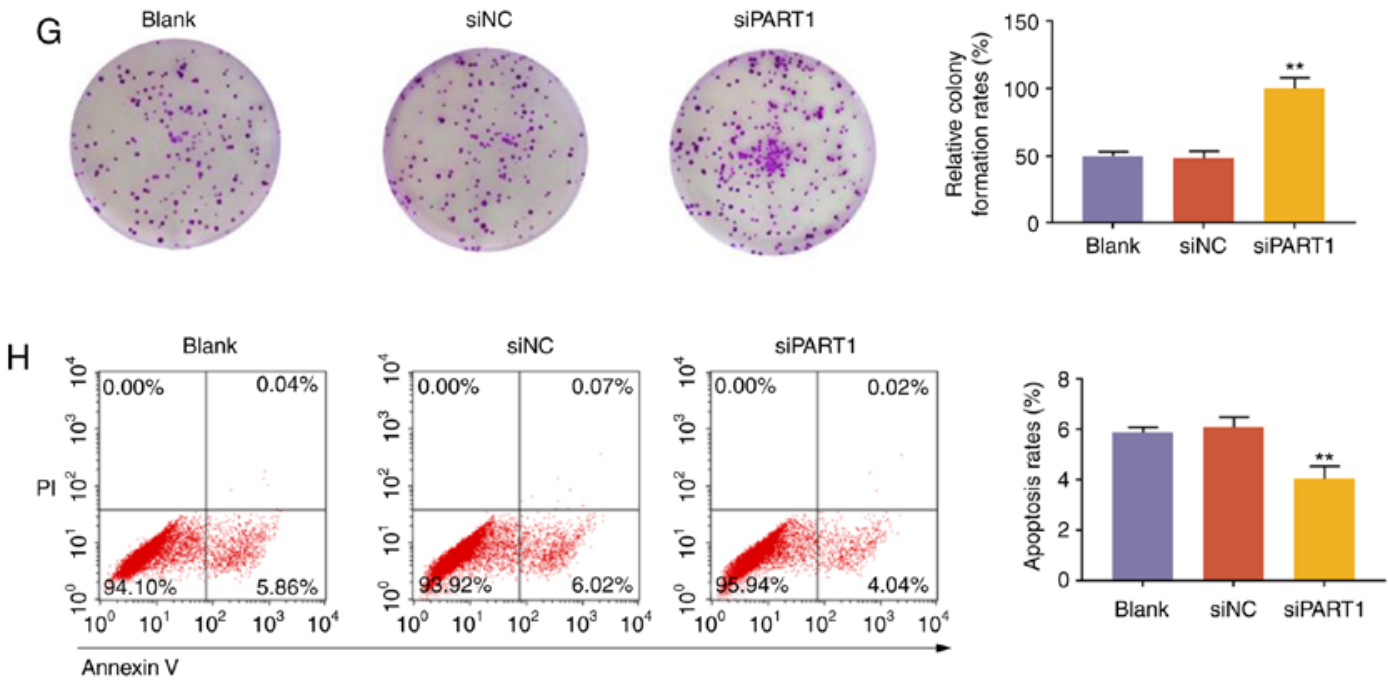

Figure 1. Expression pattern and effects of lncRNA PART1 on NP tissues. (A) Expression level of PART1 in NP tissues from IDD patients and controls. ${ }^{* *} \mathrm{P}<0.001$ vs. control. (B) The expression level of PART1 from control, bulging and herniated NP tissues was measured by quantitative PCR analysis. ${ }^{*} \mathrm{P}<0.05$ and ${ }^{* *} \mathrm{P}<0.001$ vs. control; ${ }^{\# *} \mathrm{P}<0.001$ vs. bulging. (C) NP cells were observed under an optical microscope, at a magnification of $\mathrm{x} 100$ and $\mathrm{x} 200$. (D) Immunofluorescence staining of type II collagen at a magnification of x100. (E) Expression level of PART1 in NP cells isolated from patients with IDD. (F) The proliferative capacity of NP cells was measured by Cell Counting Kit-8 assays after non-interference, or interference with siNC or siPART1 at 24, 48 and $72 \mathrm{~h}$. (G) Images of NP cell colonies. The colony formation rates are shown on the right. (H) The apoptosis of NP cells was measured by flow cytometry. $\mathrm{PI}^{+} /$Annexin $\mathrm{V}^{+}$cells were considered to be apoptotic. The apoptosis rates of $\mathrm{NP}$ cells are shown on the right.

clusters, and they were rich in cytoplasm, highly refractive, with large, clear, oval-shaped nuclei (Fig. 1C). Collagen II immunofluorescence staining revealed that the cells emitted green fluorescent light under the fluorescence microscope, which proved that the expression characteristics of the cultured cells are consistent with those of NP cells (Fig. 1D). Subsequently, NP cells were transfected with siPART1, and the expression level of PART1 was found to be reduced by siPART1 $(\mathrm{P}<0.001$, Fig. 1E). Furthermore, the CCK-8 assay demonstrated that the proliferation ability of NP cells trans- fected with siPART1 was increased $(\mathrm{P}<0.001$, Fig. $1 \mathrm{~F})$, and that the colony-forming ability of NP cells was also increased $(\mathrm{P}<0.001$, Fig. 1G). Furthermore, knockdown of PART1 inhibited the apoptosis of NP cells $(\mathrm{P}<0.001$, Fig. $1 \mathrm{H})$. In addition, the protein levels of the cell proliferation-associated protein, $\mathrm{Ki}-67$, and the apoptosis-associated protein, C-caspase-3, were measured in NP cells after interference with siPART1, and the data revealed that knockdown of PART1 promoted the expression of $\mathrm{Ki}-67$ and inhibited the expression of C-caspase-3 ( $\mathrm{P}<0.001$, Fig. 1I-J). Aggrecan and collagen II 

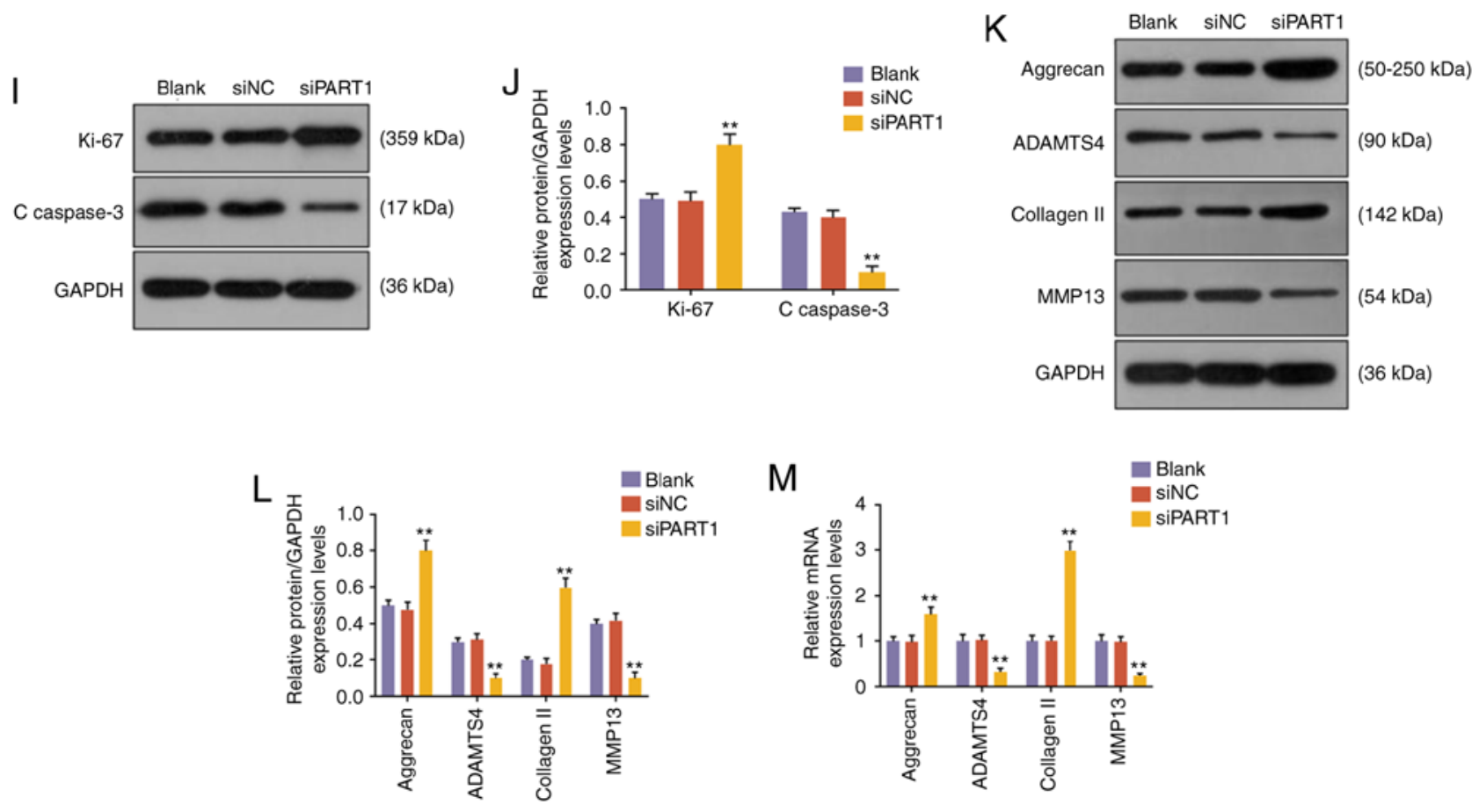

Figure 1. Continued. (I and J) The expression levels of Ki67 and C-caspase-3 in NP cells were measured by western blotting. (K-M) The expression levels of aggrecan, ADAMTS4, collagen II and MMP13 in NP cells were measured by (K and L) western blotting and (M) reverse transcription-quantitative PCR . ${ }^{* *} \mathrm{P}<0.001$ vs. siNC. Blank, non-transfection; transfection with siNC, siRNA for negative control; siPART1, siRNA for PART1; NP, nucleus pulposus; IDD, intervertebral disc degeneration.

are ECM synthesis-related genes, while ADAMTS4 and MMP13 are ECM degradation-related genes; therefore, the levels of aggrecan, collagen II, ADAMTS4 and MMP13 in NP cells with PART1 knockdown were detected by western blot and RT-qPCR analyses. The results demonstrated that siPART1 increased the levels of aggrecan and collagen II, and decreased the levels of ADAMTS4 and MMP13 $(\mathrm{P}<0.001$, Fig. 1K-M).

LncRNA PART1 regulates the expression of $m i R-93-5 p$ via sponging miR-93-5p in NP cells. DIANA-LncBase V2 (http://carolina.imis.athena-innovation.gr/, accessed January 2018) and StarBase (http://starbase.sysu.edu.c, accessed January 2018) predicted that PART1 could sponge miR-93 (Fig. 2A). StarBase predicted that PART1 could bind 35 miRNAs, and DIANA-LncBase V2 predicted that 34 miRNAs could be combined. However, only miR-93 was reported in the literature and jointly predicted by the two websites. Other miRNAs may also play a targeting role, which may be of value for future research. The prediction was confirmed by dual-luciferase reporter assay, as the results demonstrated that miR-93 inhibitor caused an increase in the luciferase activity of NP cells transfected with PART1-WT plasmid $(\mathrm{P}<0.001)$, while the luciferase activity of NP cells transfected with PART1-MUT plasmid was not affected ( $\mathrm{P}>0.05$, Fig. 2B). We then measured the expression of miR-93 in NP cells from patients with IDD or controls, and the RT-qPCR results revealed that miR-93 was downregulated in NP tissues from patients with IDD $(\mathrm{P}<0.001$, Fig. 2C). Further experiments demonstrated that knockdown of PART1 could increase the level of miR-93 ( $\mathrm{P}<0.001$, Fig. 2D). The rescue assay revealed that miR-93 mimic increased the level of miR-93, and knock- down of PART1 rescued the decrease in the miR-93 level caused by miR-93 inhibitor $(\mathrm{P}<0.001$, Fig. $2 \mathrm{E})$.

LncRNA PART1 regulates cell growth, apoptosis and ECM-related gene expression via sponging miR-93-5p in NP cells. CCK-8 and colony formation assays demonstrated that miR-93 mimic promoted and miR-93 inhibitor suppressed cell growth, which was abrogated by siPART1 (all $\mathrm{P}<0.001$, Figs. 2F and 3A). Cell apoptosis was also evaluated by flow cytometry, and the results revealed that the apoptosis rate of NP cells was reduced by miR-93 mimics and increased by miR-93 inhibitor; moreover, the increase in the apoptosis rate was rescued by knocking down PART1 (all P<0.001, Fig. 3B). Furthermore, the cell proliferation-related protein Ki-67 was upregulated by miR-93 mimics and downregulated by miR-93 inhibitor; however, these effects were abolished by siPART1 (all $\mathrm{P}<0.001$, Fig. 3C and D). In contrast to the change of the $\mathrm{Ki}-67$ level in NP cells, the level of C-caspase-3 was reduced by miR-93 mimics, increased by miR-93 inhibitor, and could be compensated by siPART1 in combination with miR-93 inhibitor treatment (all $\mathrm{P}<0.001$, Fig. $3 \mathrm{C}$ and D). Moreover, aggrecan and collagen II were upregulated, whereas ADAMTS4 and MMP13 were downregulated in NP cells transfected with miR-93 mimic, and these effects were opposite to those of the miR-93 inhibitor. In addition, the effects of the miR-93 inhibitor on ECM-related genes in NP cells were abolished by siPART1 (P<0.001, Fig. 3E-G).

miR-93 regulates the expression of $M M P 2$ through targeting the 3' untranslated region (UTR) of MMP2 in NP cells. The role of miR-93 in NP cells is unclear; thus, we sought to identify the target gene of miR-93. TargetScan predicted that the 

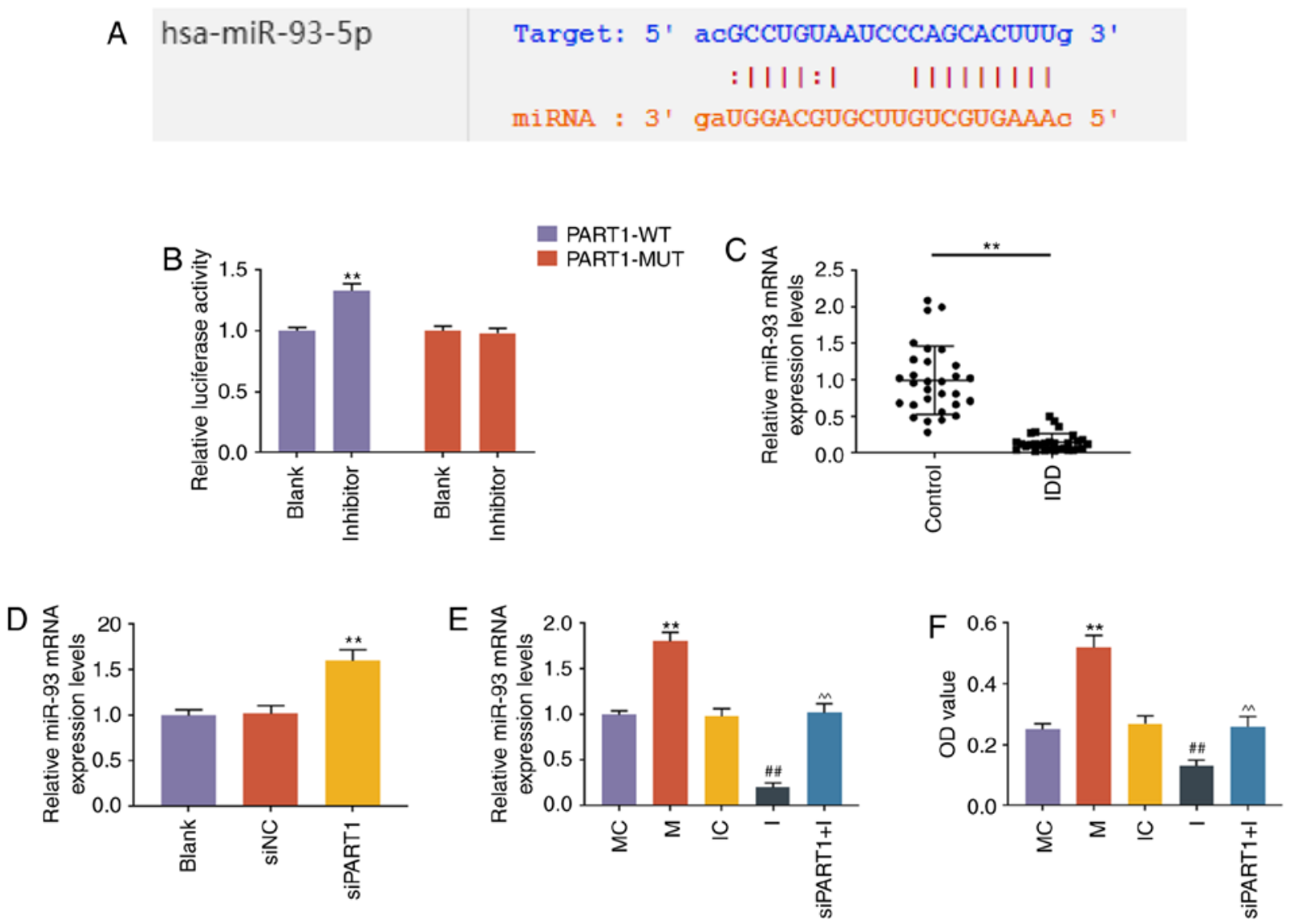

Figure 2. LncRNA PART1 regulated the expression level of miR-93-5p via sponging miR-93-5p in NP cells. (A) A potential target site for miR-93-5p in lncRNA PART1 was predicted by DIANA-LncBase V2 and starBase. (B) Dual-luciferase reporter assay was used to validate lncRNA PART1 sponging miR-93-5p in NP cells with PART1-WT reporter plasmid or PART1-MUT reporter plasmid. ${ }^{* *} \mathrm{P}<0.001$ vs. blank. (C) The expression levels of miR-93-5p in the NP tissues from IDD patients and controls were detected by RT-qPCR. ${ }^{* *} \mathrm{P}<0.001$ vs. control. (D) The expression level of miR-93-5p in the NP cells was measured by RT-qPCR. ${ }^{* *} \mathrm{P}<0.001$ vs. siNC. Blank, non-transfection; siNC, siRNA for negative control; siPART1, siRNA for PART1. (E) The expression level of miR-93-5p in NP cells was measured by RT-qPCR. " $\mathrm{P}<0.001$ vs. MC; ${ }^{\# \#} \mathrm{P}<0.001$ vs. IC; and ${ }^{\wedge} \mathrm{P}<0.001$ vs. I. MC, mimic for control; M, miR-93-5p mimics; IC, inhibitor for control; I, inhibitor for miR-93-5p; siPART1 + I, co-transfection with siRNA for PART1 and miR-93-5p inhibitor. (F) The proliferative capacity of NP cells was measured by Cell Counting Kit-8 assays. ${ }^{* *} \mathrm{P}<0.001$ vs. $\mathrm{MC}$; ${ }^{\# \#} \mathrm{P}<0.001$ vs. IC; and ${ }^{\wedge \wedge} \mathrm{P}<0.001$ vs. I. MC, mimic for control; $\mathrm{M}$, miR-93-5p mimics; IC, inhibitor for control; I, inhibitor for miR-93-5p; siPART1 + I, co-transfection with siRNA for PART1 and miR-93-5p inhibitor. NP, nucleus pulposus; WT, wild-type; MUT, mutant; IDD, intervertebral disc degeneration; RT-qPCR, reverse transcription-quantitative PCR.

target genes of miR-93-5p were from a total of 1,647 conserved sites and 914 poorly conserved sites. MMP2 was also reported to be targeted, and was therefore investigated. A potential binding site at the 3'UTR of MMP2 mRNA (515-521 nt) was predicted by TargetScan, and dual-luciferase reporter assay demonstrated that miR-93 mimic could suppress the luciferase activity in NP cells transfected with MMP2-WT reporter plasmid ( $\mathrm{P}<0.001$, Fig. 4B), while the luciferase activity in NP cells transfected with MMP2-MUT reporter plasmid was not altered (Fig. 4B). The expression level of MMP2 in NP tissues was evaluated by RT-qPCR, and the results demonstrated that MMP2 was highly expressed in NP tissues from patients with IDD $(\mathrm{P}<0.001$, Fig. 4C). A functional rescue assay revealed that the proliferation ability of NP cells was increased by miR-93 mimic, but was abrogated by MMP2 overexpression ( $\mathrm{P}<0.001$, Fig. 4D). The expression level of MMP2 in NP cells was increased by MMP2 overexpression plasmid $(\mathrm{P}<0.001$, Fig. 4E and F).

miR-93-5p regulates cell growth, apoptosis and ECM-related gene expression through targeting MMP2 in NP cells. Further experiments were performed to confirm the role of miR-93-5p in targeting MMP2 in NP cells. Colony formation assay demonstrated that overexpression of MMP2 inhibited cell growth, miR-93 mimic promoted cell growth, and the effect of miR-93 mimic on cell growth could be rescued by MMP2 overexpression (all $\mathrm{P}<0.001$, Fig. 5A). Moreover, flow cytometry analysis demonstrated that the reduction in cell apoptosis by miR-93 mimic was reversed by MMP2 overexpression (all $\mathrm{P}<0.001$, Fig. 5B). The expression of ECM-related genes was also evaluated, and results revealed that miR-93 mimic upregulated the levels of aggrecan and collagen II, and reduced the levels of ADAMTS4 and MMP13 (P<0.001, Fig. 5C-E). In addition, the effects of miR-93 mimic on ECM-related gene expression were blocked by MMP2 overexpression $(\mathrm{P}<0.001$, Fig. 5C-E).

\section{Discussion}

Delaying or reversing the degeneration of NP tissue is a promising strategy for the treatment of IDD. However, the molecular mechanisms underlying NP cell degeneration are incompletely 

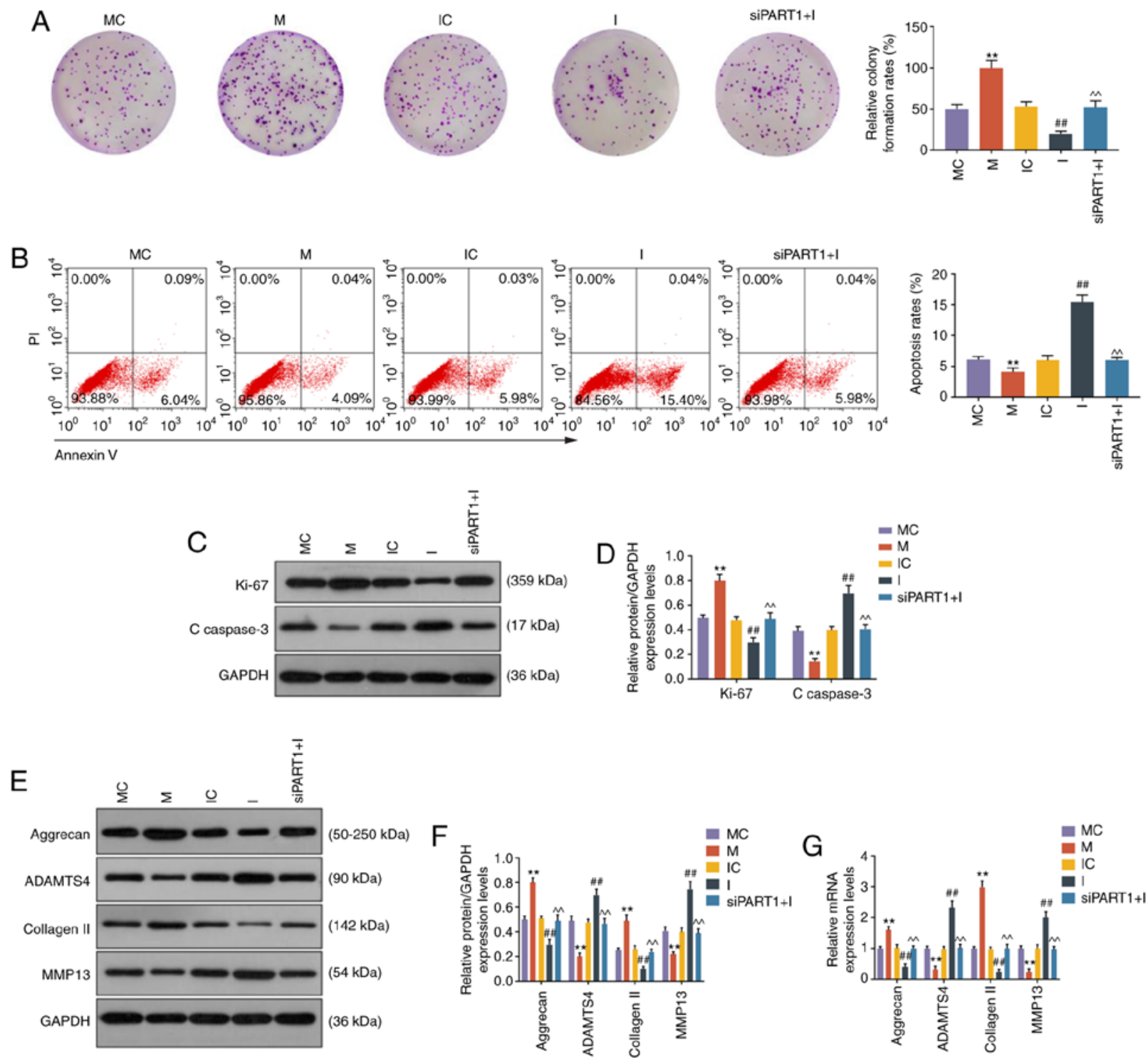

Figure 3. LncRNA PART1 regulated cell growth, apoptosis and ECM-related genes through targeting miR-93-5p. (A) Images of NP cell colonies. The colony formation rates are shown on the right. (B) The apoptosis of NP cells was measured by flow cytometry. The apoptosis rates of NP cells are shown on the right. (C and D) The expression levels of Ki67 and C-caspase-3 in NP cells were measured by western blotting. (E-G) The expression levels of aggrecan, ADAMTS4, collagen II and MMP13 in NP cells were measured by (E and F) western blotting and (G) reverse transcription-quantitative PCR analysis. ${ }^{* *} \mathrm{P}<0.001$ vs. MC; ${ }^{\# \#} \mathrm{P}<0.001$ vs. IC; and ${ }^{\wedge} \mathrm{P}<0.001$ vs. I. Blank, non-transfection; siNC, siRNA for negative control; siPART1, siRNA for PART1; MC, mimic for control; M, miR-93-5p mimics; IC, inhibitor for control; I, inhibitor for miR-93-5p; siPART1 + I, co-transfection with siRNA for PART1 and miR-93-5p inhibitor. ECM, extracellular matrix; NP, nucleus pulposus; MMP, matrix metallopeptidase.

understood. In the present study, it was observed that, in IDD patients, upregulation of the lncRNA PART1 in NP tissues and cells regulated cell growth, apoptosis, ECM production and degradation through targeting miR-93, and resulted in an increase of the MMP2 level.

Emerging studies indicate that lncRNAs are important regulators of NP cells. For example, lncRNA FAM83H-AS1 promotes the growth of NP cells through the Notch signaling pathway (19); LINC00969 promotes the development of IDD by targeting miR-335-3p and regulating NLRP3 inflammasome activation (20). In the present study, it was observed that PART1 was upregulated in degenerative NP tissues from patients with IDD, bulging and herniated discs, suggesting a potential role for PART1 in the degeneration of NP cells. The degeneration of NP tissues is directly associated with reduced numbers of NP cells, excessive apoptosis and ECM imbalance (21). Thus, the effects of PART1 knockdown on cell growth, apoptosis, and the levels of genes implicated in ECM synthesis and degradation, were investigated. NP is mainly composed of collagen type II and aggrecan (22). ADAMTS4 and MMP13 are matrix proteases that are considered to promote disc degenerative changes during aging (23). Therefore, these factors were assessed to evaluate the levels of ECM synthesis and degradation, and the results revealed that siPART1 promoted cell growth, reduced cell apoptosis and promoted ECM synthesis, which were similar to the findings of a previous study on prostate cancer (16).

Preclinical development of a microRNA-based therapy is a promising approach that is widely applied in the treatment of IDD. It has been reported that miR-141 promotes the progression of IDD and, thus, silencing of miR-141 in vivo may represent a potential therapeutic strategy (24); PART1 acts as a 


\section{A Position 515-521 of MMP2 3' UTR 5' ... CAGUJUGCUJUGUAJGCACUJUG. . . hsa-miR-93-5p 3' $\||\||||$}
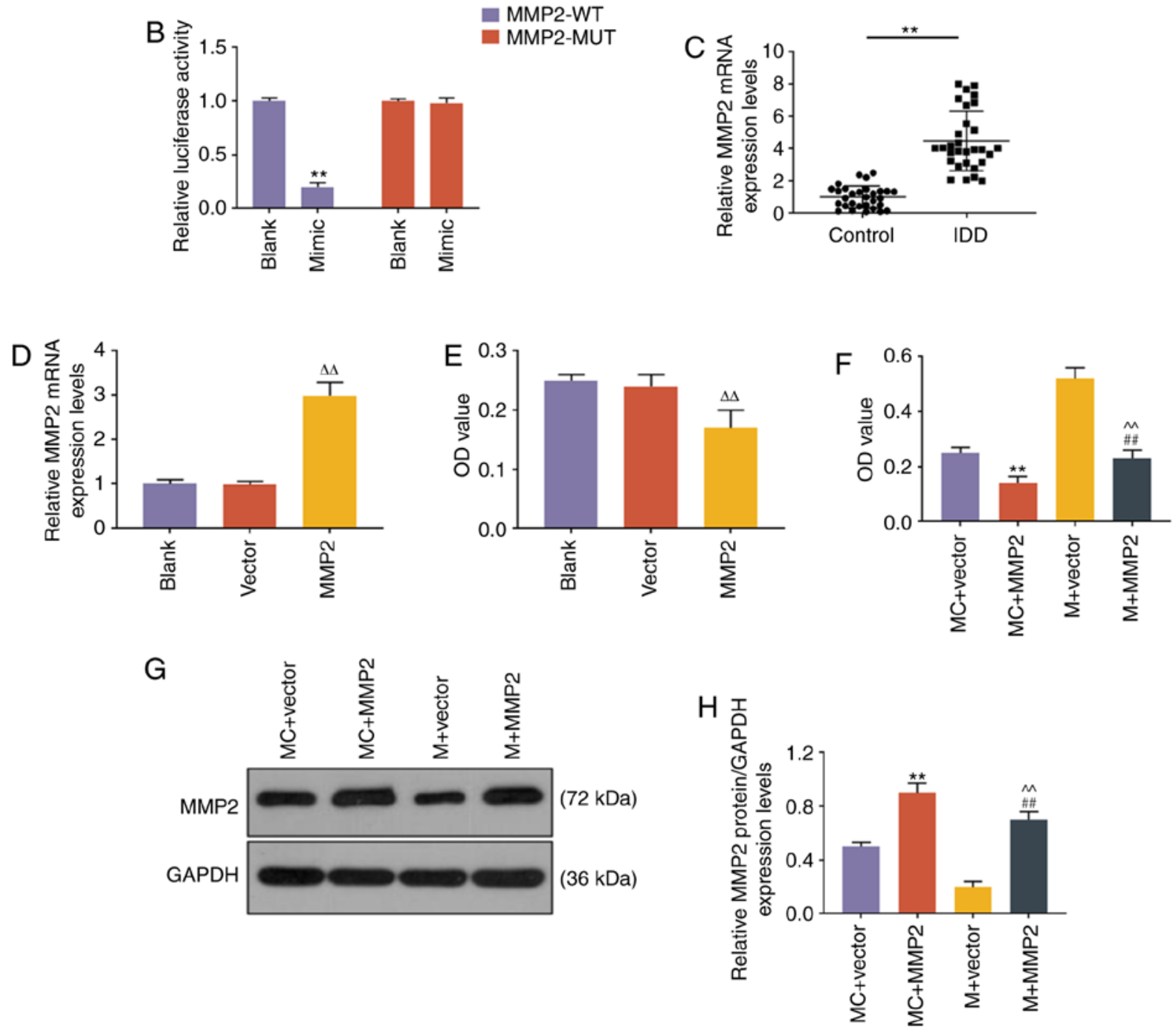

Figure 4. miR-93-5p regulated the expression of MMP2 through targeting the 3'UTR of MMP2. (A) The miR-93-5p targeting position 515-521 of MMP2 3'UTR was predicted by TargetScan. (B) Dual-luciferase reporter assay was used to validate miR-93-5p targeting MMP2 in NP cells. ${ }^{* *} \mathrm{P}<0.001$ vs. Blank. (C) The expression level of MMP2 in NP tissues from IDD patients and controls was detected by RT-qPCR analysis. ** P<0.001 vs. control. (D) RT-qPCR was applied to measure the mRNA expression levels of MMP2 after MMP2 overexpression plasmid transfection. (E) Proliferative capacity of cells transfected with MMP2. (F) The proliferative capacity of NP cells was measured by Cell Counting Kit- 8 assays. ${ }^{* *} \mathrm{P}<0.001$ vs. $\mathrm{MC}+\mathrm{vector} ;{ }^{\# \#} \mathrm{P}<0.001 \mathrm{vs}$. $\mathrm{M}+\mathrm{vector} ;{ }^{\wedge} \mathrm{P}<0.001$ vs. $\mathrm{MC}+\mathrm{MMP} 2$; and ${ }^{\Delta \Delta} \mathrm{P}<0.001$ vs. vector. $(\mathrm{G}$ and $\mathrm{H})$ The expression level of MMP2 in NP cells was measured by western blotting. ${ }^{* *} \mathrm{P}<0.001$ vs. MC + vector; ${ }^{\# \#} \mathrm{P}<0.001$ vs. $\mathrm{M}+$ vector; ${ }^{\wedge} \mathrm{P}<0.001$ vs. $\mathrm{MC}+\mathrm{MMP} 2$. Vector, transfection with empty vector for overexpression; MC + vector, co-transfection with mimic control and empty vector for overexpression; MC + MMP2, co-transfection with mimic control and MMP2 overexpression vector; M + vector, co-transfection with miR-93-5p mimic and empty vector for overexpression; M + MMP2, co-transfection with miR-93-5p mimic and MMP2 overexpression vector; MMP, matrix metallopeptidase; UTR, untranslated region; NP, nucleus pulposus; RT-qPCR, reverse transcription-quantitative PCR; IDD, intervertebral disc degeneration; WT, wild-type; MUT, mutant.

competitive endogenous RNA for promoting tumor progression through targeting miR-143 in colorectal cancer (25); and PART1 enhances gefitinib resistance by binding to miR-129 to facilitate Bcl-2 expression in esophageal squamous cell carcinoma cells (17). The present study demonstrated that PART1 targeted and regulated the expression of miR-93 in NP cells. Conversely, the expression level of miR-93 was reduced in NP tissues from IDD patients. Previous studies indicated that miR-93 can be sponged by various lncRNAs, such as lncRNA BGL3 (26),
lncRNA MEG3 (27), IncRNA MIAT (28), LINC01567 (29) and lnc-NTF3-5 (30), which play important roles in normal as well as cancerous tissues. In the present study, miR-93 was predicted to be a downstream target of lncRNA PART1 in NP cells, and it was shown to regulate cell growth, apoptosis and the expression of ECM-related genes. To the best of our knowledge, these findings have not been reported previously. The biological function of miR-93 has been extensively investigated, and miR-93 was found to be a gastric tumor-related miRNA that targets and regulates 

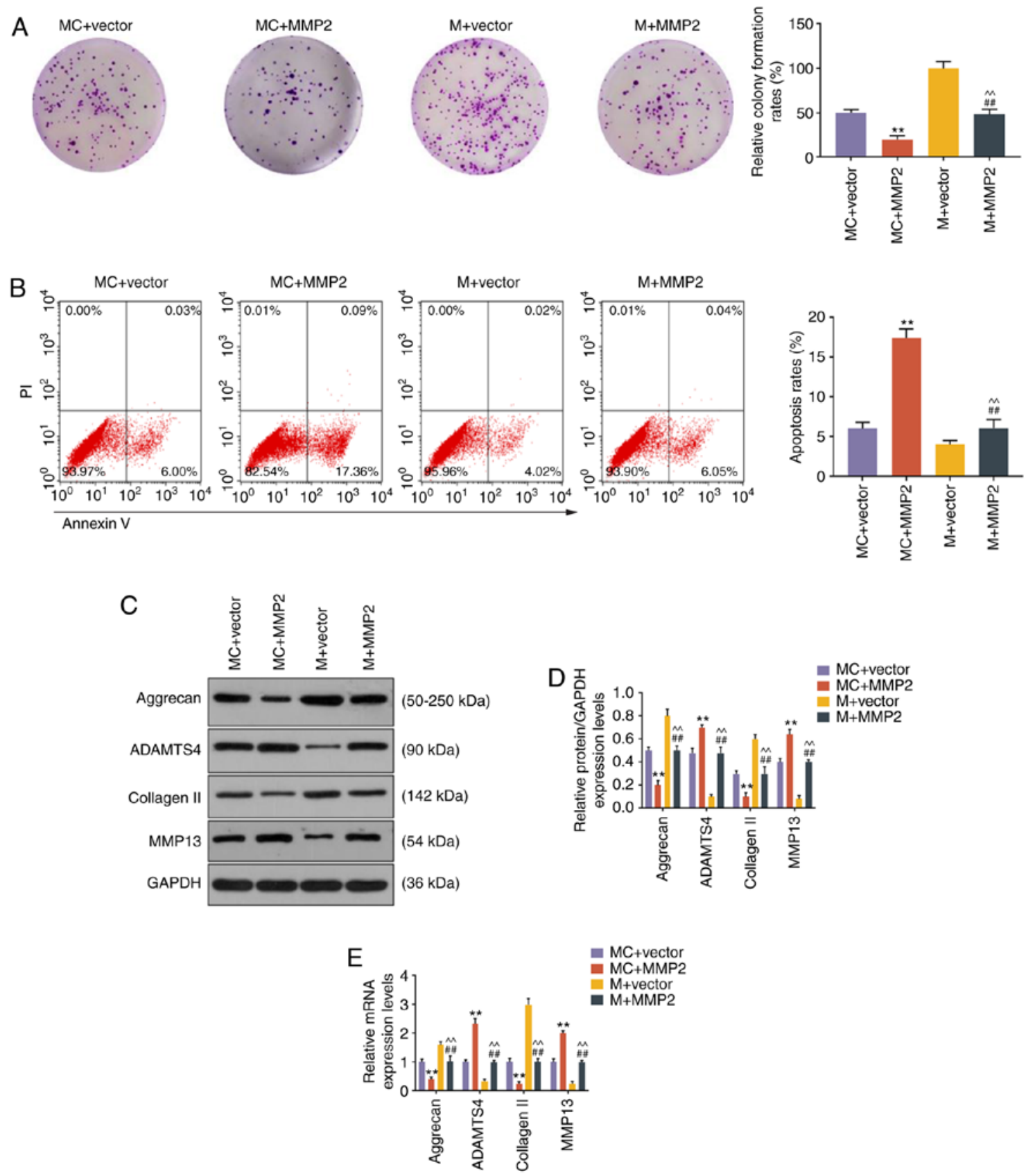

Figure 5. miR-93-5p regulated cell growth, apoptosis and ECM-related genes through targeting MMP2. (A) Images of NP cell colonies. The colony formation rates are shown on the right. (B) The apoptosis of NP cells was measured by flow cytometry. The apoptosis rates of NP cells are shown on the right. (C-E) The expression levels of aggrecan, ADAMTS4, collagen II and MMP13 in NP cells were measured by (C and D) western blotting and (E) reverse transcription-quantitative $\mathrm{PCR}$ analysis. ${ }^{* *} \mathrm{P}<0.001$ vs. $\mathrm{MC}+$ vector; ${ }^{\# \#} \mathrm{P}<0.001$ vs. $\mathrm{MC}+\mathrm{MMP} 2 ;{ }^{\wedge} \mathrm{P}<0.001$ vs. $\mathrm{M}+$ vector. $\mathrm{MC}+$ vector, co-transfection with mimic control and empty vector for overexpression; MC + MMP2, co-transfection with mimic control and MMP2 overexpression vector; M + vector, co-transfection with miR-93-5p mimic and empty vector for overexpression; M + MMP2, co-transfection with miR-93-5p mimic and MMP2 overexpression vector; ECM, extracellular matrix; NP, nucleus pulposus; MMP, matrix metallopeptidase.

E2F1 expression, and forms a negative feedback loop (31). miR-93 was also found to be involved in chromatin reorganization and progression of diabetic nephropathy by modulating Msk2 and its substrate, H3S10 (32). Furthermore, miR-93 induces repression of cGAS during hypoxia through regulating NCOA3 (33); it also affects the proliferation of fibroblasts and deposition of ECM through regulating c-Ski (34). A previous study also reported that ECM accumulation in uterine leiomyoma tissues is affected by the expression of certain miRNAs, including miR-93 (35). It should be noted that the effects of PART1 on NP cells via miR-93 must be further verified in vivo.
In the present study, miR-93 was also shown to target and regulate the expression of MMP2 in NP cells. The expression level of MMP2 in NP tissues from patients with IDD was upregulated, which was opposite to the expression of miR-93. Functional rescue assays also confirmed that miR-93 regulated cell growth, apoptosis and expression of ECM-related genes through targeting MMP2. MMP2, which is a member of the MMP gene family, is an ECM degradation enzyme and is involved in signal transduction. Integrative bioinformatics analysis and functional experiments indicated that the MMP2 signaling pathway is closely associated with the initiation 
and development of IDD (36,37). MMP2 was also found to be implicated in the proliferation of pancreatic and breast cancer cells (38). MMP2 can be targeted by several other microRNAs, such as miR-29b (39) and miR-34a (40), and it was herein verified that miR-93 directly targets MMP2 and plays an important role in NP cells.

In conclusion, IncRNA PART1 promotes degeneration of NP cells, and it regulates cell proliferation, apoptosis and the expression of ECM-related genes through targeting miR-93, resulting in increased MMP2 levels. Taken together, the findings of the present study indicate the presence of a novel signaling axis in NP cells that may be further explored for IDD treatment.

\section{Acknowledgements}

Not applicable.

\section{Funding}

No funding was received.

\section{Availability of data and materials}

The datasets used and/or analyzed during the present study are available from the corresponding author on reasonable request.

\section{Authors' contributions}

DG and LH made substantial contributions to conception and design; data acquisition, analysis and interpretation were performed by DG, LH and ZZ; DG, LH and ZZ drafted the article and critically revised it for important intellectual content. All authors have read and approved the final version of the manuscript for publication. All authors agree to be accountable for all aspects of the work in ensuring that questions related to the accuracy or integrity of the work are appropriately investigated and resolved.

\section{Ethics approval and consent to participate}

All procedures involving human participants were in accordance with the ethical standards of the institutional and/or national research committee and with the 1964 Helsinki Declaration and its later amendments or comparable ethical standards.

\section{Patient consent for publication}

Not applicable.

\section{Competing interests}

The authors declare that they have no competing interests.

\section{References}

1. van Uden S, Silva-Correia J, Oliveira JM and Reis RL: Current strategies for treatment of intervertebral disc degeneration: Substitution and regeneration possibilities. Biomater Res 21: 22, 2017.
2. Priyadarshani P, Li Y and Yao L: Advances in biological therapy for nucleus pulposus regeneration. Osteoarthritis Cartilage 24: 206-212, 2016.

3. He F and Pei M: Rejuvenation of nucleus pulposus cells using extracellular matrix deposited by synovium-derived stem cells. Spine (Phila Pa 1976) 37: 459-469, 2012.

4. Li P, Liang Z, Hou G, Song L, Zhang R, Gan Y, Zhang C, Xu Y and Zhou Q: N-Cadherin-mediated activation of PI3K/Akt-GSK-3 $\beta$ signaling attenuates nucleus pulposus cell apoptosis under high-magnitude compression. Cell Physiol Biochem 44: 229-239, 2017.

5. Clarke LE, McConnell JC, Sherratt MJ, Derby B, Richardson SM and Hoyland JA: Growth differentiation factor 6 and transforming growth factor-beta differentially mediate mesenchymal stem cell differentiation, composition, and micromechanical properties of nucleus pulposus constructs. Arthritis Res Ther 16: R67, 2014.

6. Chen J, Xie JJ, Jin MY, Gu YT, Wu CC, Guo WJ, Yan YZ, Zhang ZJ, Wang JL, Zhang XL, et al: Sirt6 overexpression suppresses senescence and apoptosis of nucleus pulposus cells by inducing autophagy in a model of intervertebral disc degeneration. Cell Death Dis 9: 56, 2018.

7. Wang W, Li P, Xu J, Wu X, Guo Z, Fan L, Song R, Wang J, Wei L and Teng $\mathrm{H}$ : Resveratrol attenuates high glucose-induced nucleus pulposus cell apoptosis and senescence through activating the ROS-mediated PI3K/Akt pathway. Biosci Rep 38: BSR20171454, 2018.

8. Séguin CA, Pilliar RM, Roughley PJ and Kandel RA: Tumor necrosis factor-alpha modulates matrix production and catabolism in nucleus pulposus tissue. Spine (Phila Pa 1976) 30: 1940-1948, 2005.

9. Li P, Gan Y, Xu Y, Song L, Wang L, Ouyang B, Zhang C and Zhou Q: The inflammatory cytokine TNF- $\alpha$ promotes the premature senescence of rat nucleus pulposus cells via the PI3K/Akt signaling pathway. Sci Rep 7: 42938, 2017.

10. Li P, Gan Y, Xu Y, Wang L, Ouyang B, Zhang C, Luo L, Zhao C and Zhou Q: 17beta-estradiol attenuates TNF- $\alpha$-induced premature senescence of nucleus pulposus cells through regulating the ROS/NF- $\kappa \mathrm{B}$ pathway. Int J Biol Sci 13: 145-156, 2017.

11. Wan ZY, Song F, Sun Z, Chen YF, Zhang WL, Samartzis D, Ma CJ, Che L, Liu X, Ali MA, et al: Aberrantly expressed long noncoding RNAs in human intervertebral disc degeneration: A microarray related study. Arthritis Res Ther 16: 465, 2014.

12. Chen WK, Yu XH, Yang W, Wang C, He WS, Yan YG, Zhang J and Wang WJ: lncRNAs: Novel players in intervertebral disc degeneration and osteoarthritis. Cell Prolif 50: 2017.

13. Zhang S, Cao R, Li Q, Yao M, Chen Y and Zhou H: Comprehensive analysis of lncRNA-associated competing endogenous RNA network in tongue squamous cell carcinoma. PeerJ 7: e6397, 2019.

14. Lv Y, Wei W, Huang Z, Chen Z, Fang Y, Pan L, Han X and Xu Z: Long non-coding RNA expression profile can predict early recurrence in hepatocellular carcinoma after curative resection. Hepatol Res 48: 1140-1148, 2018.

15. Li M, Zhang W, Zhang S, Wang C and Lin Y: PART1 expression is associated with poor prognosis and tumor recurrence in stage I-III non-small cell lung cancer. J Cancer 8: 1795-1800, 2017.

16. Sun M, Geng D, Li S, Chen Z and Zhao W: LncRNA PART1 modulates toll-like receptor pathways to influence cell proliferation and apoptosis in prostate cancer cells. Biol Chem 399: 387-395, 2018.

17. Kang M,Ren M,Li Y,Fu Y, Deng M and Li C: Exosome-mediated transfer of lncRNA PART1 induces gefitinib resistance in esophageal squamous cell carcinoma via functioning as a competing endogenous RNA. J Exp Clin Cancer Res 37: 171, 2018.

18. Wei R, Chen Y,Zhao Z, Gu Q and Wu J: LncRNA FAM83H-AS1 induces nucleus pulposus cell growth via targeting the Notch signaling pathway. J Cell Physiol 234: 22163-22171, 2019.

19. Yu L, Hao Y, Xu C, Zhu G and Cai Y: LINC00969 promotes the degeneration of intervertebral disk by sponging miR-335-3p and regulating NLRP3 inflammasome activation. IUBMB Life 71: 611-618, 2019.

20. Cheng X, Zhang L, Zhang K, Zhang G, Hu Y, Sun X, Zhao C, Li H, Li YM and Zhao J: Circular RNA VMA21 protects against intervertebral disc degeneration through targeting miR-200c and X linked inhibitor-of-apoptosis protein. Ann Rheum Dis 77: 770-779, 2018. 
21. Mern DS, Fontana J, Beierfuß A, Thomé C and Hegewald AA: A combinatorial relative mass value evaluation of endogenous bioactive proteins in three-dimensional cultured nucleus pulposus cells of herniated intervertebral discs: Identification of potential target proteins for gene therapeutic approaches. PLoS One 8: e81467, 2013.

22. Patil P, Dong Q, Wang D, Chang J, Wiley C, Demaria M, Lee J, Kang J, Niedernhofer LJ, Robbins PD, et al: Systemic clearance of p16 $6^{\text {INK4a }}$-positive senescent cells mitigates age-associated intervertebral disc degeneration. Aging Cell 18: e12927, 2019.

23. Ji ML, Jiang H, Zhang XJ, Shi PL, Li C, Wu H, Wu XT, Wang YT, Wang $\mathrm{C}$ and $\mathrm{Lu} \mathrm{J}$ : Preclinical development of a microRNA-based therapy for intervertebral disc degeneration. Nat Commun 9 : 5051,2018

24. Hu Y, Ma Z, He Y, Liu W, Su Y and Tang Z: PART-1 functions as a competitive endogenous RNA for promoting tumor progression by sponging miR-143 in colorectal cancer. Biochem Biophys Res Commun 490: 317-323, 2017.

25. Guo G, Kang Q, Zhu X, Chen Q, Wang X, Chen Y, Ouyang J, Zhang L, Tan H, Chen R, et al: A long noncoding RNA critically regulates Bcr-Abl-mediated cellular transformation by acting as a competitive endogenous RNA. Oncogene 34: 1768-1779, 2015.

26. Zhang L, Liang X and Li Y: Long non-coding RNA MEG3 inhibits cell growth of gliomas by targeting miR-93 and inactivating PI3K/AKT pathway. Oncol Rep 38: 2408-2416, 2017.

27. Li Y, Wang J, Sun L and Zhu S: LncRNA myocardial infarction-associated transcript (MIAT) contributed to cardiac hypertrophy by regulating TLR4 via miR-93. Eur J Pharmacol 818: 508-517, 2018

28. Yu X, Mi L, Dong J and Zou J: Long intergenic non-protein-coding RNA 1567 (LINC01567) acts as a 'sponge' against microRNA-93 in regulating the proliferation and tumorigenesis of human colon cancer stem cells. BMC Cancer 17: 716, 2017.

29. Peng W, Zhu SX, Wang J, Chen LL, Weng JQ and Chen SL: Lnc-NTF3-5 promotes osteogenic differentiation of maxillary sinus membrane stem cells via sponging miR-93-3p. Clin Implant Dent Relat Res 20: 110-121, 2018.

30. Petrocca F, Visone R, Onelli MR, Shah MH, Nicoloso MS de Martino I, Iliopoulos D, Pilozzi E, Liu CG, Negrini M, et al: E2F1-regulated microRNAs impair TGFbeta-dependent cell-cycle arrest and apoptosis in gastric cancer. Cancer cell 13: 272-286, 2008.

31. Badal SS, Wang Y, Long J, Corcoran DL, Chang BH, Truong LD, Kanwar YS, Overbeek PA and Danesh FR: miR-93 regulates Msk2-mediated chromatin remodelling in diabetic nephropathy. Nat Commun 7: 12076, 2016.
32. Wu MZ, Cheng WC, Chen SF, Nieh S, O'Connor C, Liu CL, Tsai WW, Wu CJ, Martin L, Lin YS, et al: miR-25/93 mediates hypoxia-induced immunosuppression by repressing cGAS. Nat Cell Biol 19: 1286-1296, 2017.

33. Zhang C, Zhang Y, Zhu H, Hu J and Xie Z: MiR-34a/miR-93 target c-Ski to modulate the proliferaton of rat cardiac fibroblasts and extracellular matrix deposition in vivo and in vitro. Cell Signal 46: 145-153, 2018.

34. Islam MS, Ciavattini A, Petraglia F, Castellucci M and Ciarmela P: Extracellular matrix in uterine leiomyoma pathogenesis: A potential target for future therapeutics. Hum Reprod Update 24: 59-85, 2018.

35. Xunlu Y, Minshan F, Liguo Z, Jiawen Z, Xu W, Jie Y, Shangquan W, He Y, Long L, Tao H and Xuepeng L: Integrative bioinformatics analysis reveals potential gene biomarkers and analysis of function in human degenerative disc annulus fibrosus cells. Biomed Res Int 2019: 9890279, 2019.

36. Ji ML, Lu J, Shi PL, Zhang XJ, Wang SZ, Chang Q, Chen H and Wang C: Dysregulated miR-98 contributes to extracellular matrix degradation by targeting IL-6/STAT3 signaling pathway in human intervertebral disc degeneration. J Bone Miner Res 31: 900-909, 2016.

37. Han Y, Ma L, Zhao L, Feng W and Zheng X: Rosmarinic inhibits cell proliferation, invasion and migration via up-regulating miR-506 and suppressing MMP2/16 expression in pancreatic cancer. Biomed Pharmacother 115: 108878, 2019.

38. Li Y, Su X and Pan H: Inhibition of IncRNA PANDAR reduces cell proliferation, cell invasion and suppresses EMT pathway in breast cancer. Cancer Biomark 25: 185-192, 2019.

39. Wang T, Hou J, Jian S, Luo Q, Wei J, Li Z, Wang X, Bai P, Duan B, Xing J and Cai J: miR-29b negatively regulates MMP2 to impact gastric cancer development by suppress gastric cancer cell migration and tumor growth. J Cancer 9: 3776-3786, 2018.

40. Yang L, Song X, Zhu J, Li M, Ji Y, Wu F, Chen Y, Cui X, Hu J, Wang L, et al: Tumor suppressor microRNA-34a inhibits cell migration and invasion by targeting MMP-2/MMP-9/FNDC3B in esophageal squamous cell carcinoma. Int J Oncol 51: 378-388, 2017.

This work is licensed under a Creative Commons Attribution-NonCommercial-NoDerivatives 4.0 International (CC BY-NC-ND 4.0) License. 